\title{
A CASE OF OSMOTIC ENCEPHALOPATHY IN OSMOTIC DEMYELINATION SYNDROME WITH SEVERE HYPERNATREMIA
}

\author{
Pavan D. Patel1, Amit Botre2, Aparna Patange 3 , Nitin Jadhav ${ }^{4}$, Harsh Shah ${ }^{5}$
}

${ }_{1}^{1}$ Resident, Department of General Medicine, Krishna Institute of Medical Sciences, Karad, Maharashtra, India. ${ }^{2}$ Assistant Professor, Department of General Medicine, Krishna Institute of Medical Sciences, Karad, Maharashtra, India. ${ }^{3}$ Associate Professor, Department of General Medicine, Krishna Institute of Medical Sciences, Karad, Maharashtra, India. ${ }^{4}$ Associate Professor, Department of General Medicine, Krishna Institute of Medical Sciences, Karad, Maharashtra, India. ${ }^{5}$ Resident, Department of General Medicine, Krishna Institute of Medical Sciences, Karad, Maharashtra, India.

HOW TO CITE THIS ARTICLE: Patel PD, Botre A, Patange A, et al. A case of osmotic encephalopathy in osmotic demyelination syndrome with severe hypernatremia. J. Evolution Med. Dent. Sci. 2019;8(11):819-820, DOI: 10.14260/jemds/2019/181

\section{PRESENTATION OF CASE}

30-year-old male patient was brought by relatives to ER of Krishna hospital in altered state of consciousness and was unable to speak, patient was found unconscious in sewage pipe in Mumbai, was taken to nearby hospital, received primary medical attention, and was later transferred to Karad by relatives for further management. Relatives gave history that patient had absconded from job and was found unconscious in sewage canal. On examination, patient was stuporous, no eye opening, extension to painful stimuli. patient was severely dehydrated with pulse rate of 140 per minute, low volume, blood pressure was $70 \mathrm{mmHg}$ systolic with agonal breaths.

Hypernatremia is a potentially lethal condition, and can cause encephalopathy, rhabdomyolysis, and osmotic demyelination syndrome.[1]

Extrapontine myelinolysis (EPM) is a common metabolic disorder and it is associated with neurological complications. Central pontine myelinolysis (CPM) and extrapontine myelinolysis (EPM) are often seen with rapid correction of serum sodium. However, Myelinolysis, is rarely seen to be associated with hypernatremia. The present case was a rare case of hypovolemic hypernatremia with associated osmotic encephalopathy and acute kidney injury due to severe dehydration. The serum sodium levels in the present case were as high as $182 \mathrm{mEq} / \mathrm{l}$ on presentation.

\section{CLINICAL DIAGNOSIS}

The patient was immediately shifted to ICU, basic blood investigations were sent, patients received IV fluid resuscitation, central venous catheter was inserted, CVP recorded 3-4 cm of water. Patient received CVP guided fluid, laboratory investigations revealed serum sodium $182 \mathrm{mEq} / \mathrm{l}$, serum potassium $5.3 \mathrm{mEq} / \mathrm{l}$. Haemoglobin level was $17.0 \mathrm{~g} / \mathrm{dl}$ with blood urea more than 200 and serum creatinine was $2.3 \mathrm{mg} / \mathrm{dl}$. Patient's urinary sodium was $304 \mathrm{mEq} /$ Day (Ref Range $=44-220$ ) and urinary potassium was $56.5 \mathrm{mEq} /$ Day (Ref Range=25-120). ABG revealed similar serum electrolyte picture with severe metabolic acidosis with compensatory respiratory acidosis.

'Financial or Other Competing Interest': None.

Submission 27-12-2018, Peer Review 01-03-2019,

Acceptance 08-03-2019, Published 18-03-2019.

Corresponding Author:

Dr. Pavan D. Patel,

Resident, Department of General Medicine,

Krishna Institute of Medical Sciences,

Karad, Satara-415110, Maharashtra, India.

E-mail: researchexpert3@gmail.com

DOI: $10.14260 /$ jemds $/ 2019 / 181$

\section{(c) $(1)$}

Patient's sensorium improved marginally, was disoriented, obeying simple verbal commands intermittently, MRI Brain was considered to rule out cerebral insult, MRI Brain was suggestive of osmotic encephalopathy. (with the below features)-
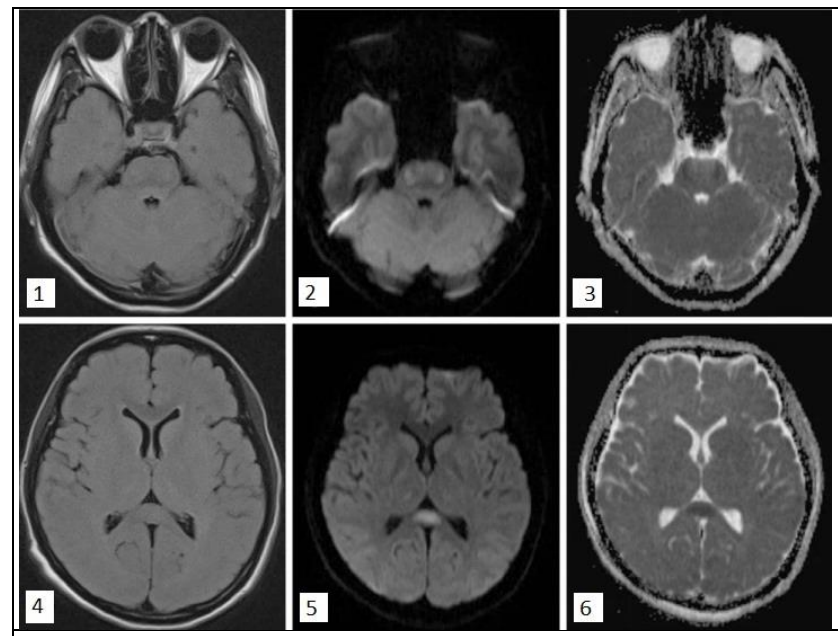

Multifocal Diffusion Restriction in Bilateral Thalami and Pons on DWI (2 and 5) and Low Signal Intensity Lesion in the Similar Portion on ADC Maps (3 and 6). There was very Subtle High Signal Intensity Lesions in Bilateral Central Pons on the Flair Images (1 and 4).

[DWI: diffusion-weighted image, ADC: apparent diffusion coefficient, FLAIR: fluid-attenuated inversion recovery, MRI: magnetic resonance image]; patient received IV corticosteroids and supportive treatment. His serum sodium level after 5 days of critical care therapy came to $143 \mathrm{mEq} / \mathrm{L}$, after that patient recovered and further patient developed gag reflex with normal sensorium and orientation, later patient was shifted to ward. After 9 days of hospital stay, patient got routine discharge with no neurological abnormality and now patient is living a normal life.

\section{PATHOLOGICAL DISCUSSION}

Severe hypernatremia can be defined as raised serum sodium levels more than $160 \mathrm{mEq} / \mathrm{L}$. Severe hypernatremia often results in failure of the defence mechanism system of the brain to adapt itself to the change. And it is responsible for high mortality due to encephalopathy.[2,3]

Hypernatremia is quite uncommon in routine days. Hypernatremia which is potentially lethal condition which can cause rhabdomyolysis, encephalopathy and osmotic demyelination.[1] it leads to permanent neurologic symptoms and is associated with high mortality. 
Osmotic Demyelination syndrome (ODS) often occurs as a result of rapid correction of hyponatremia, but rarely ODS may occur in case of severe hypernatremia. However, the mechanism of Osmotic Demyelination syndrome in case of hypernatremia is not well understood. Based on the data available from previous animal studies, marked hypernatremia due to rapid correction of hyponatremia may cause myelinolysis in humans.[4]

Spectrum of pathological changes observed in Osmotic Demyelination syndrome includes Central pontine myelinolysis and extra-pontine myelinolysis, which can be reported on computed tomography. However, Magnetic Resonance Imaging is the technique of choice for diagnosis of ODS, since it has greater sensitivity and capacity for demonstration of the CPM and EPM lesions.[5] On T2weighted MRI, Central pontine myelinolysis represents a hyperintense, trident-shaped, symmetric lesion in the central pons with sparing of the periphery. And hypointensity on the T1-weighted image.[6] In extra-pontine myelinolysis cases, these features are observed frequently in the corpus callosum, basal ganglia, hippocampus, lateral geniculate body, thalamus, cerebellum, and cerebral subcortex, and it is observed infrequently in the midbrain, internal capsule, and medulla oblongata.[1,7] Our patient's MRI brain was suggestive of osmotic encephalopathy.

\section{DISCUSSION OF MANAGEMENT}

The principles behind the management of hypernatremia are mainly the correction of the underlying causes and hence the resulting hypertonicity. In the management of hypernatremia, the rate of correction of hypernatremia is of utmost importance, since it results in brain oedema. According to the recommendations, correction that reduce the serum sodium concentration by $1 \mathrm{mEq} / \mathrm{L} /$ hour improves the prognosis. To prevent cerebral oedema, for longer or unknown duration, reduction in the serum sodium concentration at a maximal rate of $0.5 \mathrm{mEq} / \mathrm{L} / \mathrm{hour}$ or $10 \mathrm{mEq} / \mathrm{L} /$ day is recommended.(8)

In the present case, the correction rate of hypernatremia was $13 \mathrm{mEq} / \mathrm{L}$ over the first 24 hours, which was nearer to the standard recommended rate of correction. Our case did not develop Complications such as Brain oedema or convulsions were not reported.

\begin{tabular}{|c|c|c|c|c|c|c|}
\hline \multirow[t]{2}{*}{ 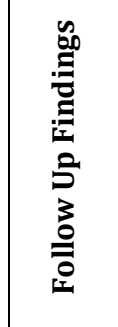 } & 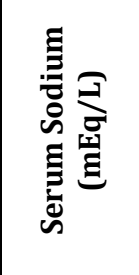 & 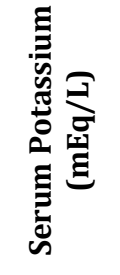 & 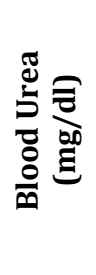 & 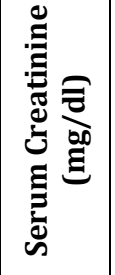 & 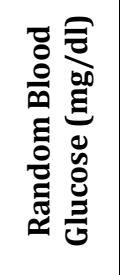 & $\begin{array}{l}\overrightarrow{0} \\
\underset{0}{0} \\
0 \\
0\end{array}$ \\
\hline & $136-145$ & $3.5-5.1$ & $13-43$ & $0.7-1.3$ & $80-120$ & $13-17$ \\
\hline Day 1 & 182 & 5.3 & 209 & \begin{tabular}{|l|}
2.3 \\
\end{tabular} & 112 & 17 \\
\hline Day 2 & 168 & 3.7 & 178 & 1.9 & 123 & 15.6 \\
\hline Day 3 & 156 & 3.2 & 203 & 2 & 134 & 11.2 \\
\hline Day 4 & 144 & 3.3 & 121 & 1.2 & 99 & 11.6 \\
\hline Day 5 & 142 & 3.4 & 99 & 1 & 138 & 11.2 \\
\hline Day 6 & 141 & 3.3 & 45 & 0.7 & 112 & 11.5 \\
\hline Day 7 & 141 & 3.4 & 35 & 0.9 & 96 & 10 \\
\hline Day 8 & 140 & 3.8 & 26 & 0.7 & 129 & 11.1 \\
\hline Day 9 & 139 & 3.5 & 25 & 0.7 & 104 & 10.8 \\
\hline
\end{tabular}

According to the recent medical literature, it has been reported that the corticosteroids may improve the outcome in cases of hypernatraemic demyelination. Animal studies had revealed that Dexamethasone protected against osmotic induced demyelination in rats by protecting the brain blood barrier.[1],[9]

However, the present case was treated with $0.45 \%$ saline and 5\% dextrose water and IV dexamethasone $5 \mathrm{mg}$ and hydrocortisone $100 \mathrm{mg} /$ day. We used steroids solely to prevent adrenal insufficiency; hence, we do not know exactly what are the effects of corticosteroid therapy for prevention of ODS.

\section{FINAL DIAGNOSIS}

Hypernatremia with osmotic encephalopathy caused by severe dehydration.

It was successfully treated with corticosteroids and IV fluids. It confirms the importance of adequate fluids and corticosteroid supplementation in severe hypernatremia.

\section{REFERENCES}

[1] Naik KR, Saroja AO. Seasonal postpartum hypernatremic encephalopathy with osmotic extrapontine myelinolysis and rhabdomyolysis. J Neurol Sci 2010;291(1-2):5-11.

[2] Samuels MA, Seifter JL. Encephalopathies caused by electrolyte disorders. Semin Neurol 2011;31(2):135-8.

[3] Arieff AI. Central nervous system manifestations of disordered sodium metabolism. Clin Endocrinol Metab 1984;13(2):269-94.

[4] Ayus JC, Armstrong DL, Arieff AI. Effects of hypernatraemia in the central nervous system and its therapy in rats and rabbits. J Physiol 1996;492(Pt 1):243-55.

[5] Sugimura Y, Murase T, Takefuji S, et al. Protective effect of dexamethasone on osmotic-induced demyelination in rats. Exp Neurol 2005;192(1):17883.

[6] Sakamoto E, Hagiwara D, Morishita Y, et al. Complete recovery of central pontine myelinolysis by high dose pulse therapy with methylprednisolone. Nihon Naika Gakkai Zasshi 2007;96(10):2291-3.

[7] Machino T, Yoshizawa T. Brain shrinkage due to acute hypernatremia. Neurology 2006;67(5):880.

[8] Adrogue HJ, Madias NE. Hypernatremia. N Engl J Med 2000;342(20):1493-9.

[9] Adler S, Verbalis JG, Meyers S, et al. Changes in cerebral blood flow and distribution associated with acute increases in plasma sodium and osmolality of chronic hyponatremic rats. Exp Neurol 2000;163(1):63-71. 